\title{
Intermediate-term mortality and cardiac transplantation in infants with single-ventricle lesions: Risk factors and their interaction with shunt type
}

\author{
James S. Tweddell, MD, ${ }^{\mathrm{a}}$ Lynn A. Sleeper, ScD, ${ }^{\mathrm{b}}$ Richard G. Ohye, MD, ${ }^{\mathrm{c}}$ Ismee A. Williams, MD, MS, ${ }^{\mathrm{d}}$ \\ Lynn Mahony, MD, ${ }^{\mathrm{e}}$ Christian Pizarro, MD,${ }^{\mathrm{f}}$ Victoria L. Pemberton, RNC, MS, ${ }^{\mathrm{g}}$ Peter C. Frommelt, MD, ${ }^{\mathrm{a}}$ \\ Scott M. Bradley, MD, James F. Cnota, MD, ${ }^{\mathrm{i}}$ Jennifer Hirsch, MD, MS, ${ }^{\mathrm{c}}$ Paul M. Kirshbom, MD, \\ Jennifer S. Li, MD, MHS, ${ }^{\mathrm{k}}$ Nancy Pike, RN, PhD, ${ }^{1}$ Michael Puchalski, MD, ${ }^{\mathrm{m}}$ Chitra Ravishankar, MD, ${ }^{\mathrm{n}}$ \\ Jeffrey P. Jacobs, MD, ${ }^{\mathrm{o}}$ Peter C. Laussen, MBBS, ${ }^{\mathrm{p}}$ and Brian W. McCrindle, MD, MPH, ${ }^{\mathrm{q}}$ for the Pediatric \\ Heart Network Investigators
}

Objective: The study objective was to identify factors associated with death and cardiac transplantation in infants undergoing the Norwood procedure and to determine differences in associations that might favor the modified Blalock-Taussig shunt or a right ventricle-to-pulmonary artery shunt.

Methods: We used competing risks methodology to analyze death without transplantation, cardiac transplantation, and survival without transplantation. Parametric time-to-event modeling and bootstrapping were used to identify independent predictors.

Results: Data from 549 subjects (follow-up, $2.7 \pm 0.9$ years) were analyzed. Mortality risk was characterized by early and constant phases; transplant was characterized by only a constant phase. Early phase factors associated with death included lower socioeconomic status $(P=.01)$, obstructed pulmonary venous return $(P<.001)$, smaller ascending aorta $(P=.02)$, and anatomic subtype. Constant phase factors associated with death included genetic syndrome $(P<.001)$ and lower gestational age $(P<.001)$. The right ventricle-to-pulmonary artery shunt demonstrated better survival in the $51 \%$ of subjects who were full term with aortic atresia $(P<.001)$. The modified Blalock-Taussig shunt was better among the $4 \%$ of subjects who were preterm with a patent aortic valve $(P=.003)$. Lower pre-Norwood right ventricular fractional area change, pre-Norwood surgery, and anatomy other than hypoplastic left heart syndrome were independently associated with transplantation (all $P<.03$ ), but shunt type was not $(P=.43)$.

Conclusions: Independent risk factors for intermediate-term mortality include lower socioeconomic status, anatomy, genetic syndrome, and lower gestational age. Term infants with aortic atresia benefited from a right ventricle-to-pulmonary artery shunt, and preterm infants with a patent aortic valve benefited from a modified Blalock-Taussig shunt. Right ventricular function and anatomy, but not shunt type, were associated with transplantation. (J Thorac Cardiovasc Surg 2012;144:152-9)

\footnotetext{
From the Medical College of Wisconsin, ${ }^{\text {a }}$ Milwaukee, Wis; New England Research Institutes, Inc, ${ }^{\mathrm{b}}$ Watertown, Mass; University of Michigan, ${ }^{\mathrm{c}}$ Ann Arbor, Mich; Columbia University, ${ }^{\mathrm{d}}$ New York, NY; University of Texas Southwestern Medical Center, ${ }^{\mathrm{e}}$ Dallas, Tex; Nemours Cardiac Center, ${ }^{\mathrm{f}}$ Wilmington, Del; National Heart, Lung, and Blood Institute, ${ }^{\mathrm{g}}$ Bethesda, Md; Medical University of South Carolina, ${ }^{\mathrm{h}}$ Charleston, SC; Cincinnati Children's Hospital, ${ }^{i}$ Cincinnati, Ohio; Emory University, ${ }^{\mathrm{j}}$ Atlanta, Ga; Duke University, ${ }^{\mathrm{k}}$ Durham, NC; Children's Hospital Los Angeles, ${ }^{1}$ Los Angeles, Calif; Primary Children's Medical Center, ${ }^{\mathrm{m}}$ Salt Lake City, Utah; The Children's Hospital of Philadelphia, ${ }^{\mathrm{n}}$ Philadelphia, Pa; Congenital Heart Institute of Florida, ${ }^{\circ}$ St Petersburg, Fla; Children's Hospital Boston, ${ }^{\mathrm{P}}$ Boston, Mass; and Hospital for Sick Children, ${ }^{\mathrm{q}}$ Toronto, Ontario, Canada.

Supported by U01 grants from the National Heart, Lung, and Blood Institute (HL068269, HL068270, HL068279, HL068281, HL068285, HL068292, HL068290, HL068288, HL085057). Its contents are solely the responsibility of the authors and do not necessarily represent the official views of the National Heart, Lung, and Blood Institute. Clinical Trial Registration NCT00115934.

Disclosures: Authors have nothing to disclose with regard to commercial support.

Received for publication Nov 8, 2011; accepted for publication Jan 4, 2012; available ahead of print Feb 17, 2012.

Address for reprints: Lynn A. Sleeper, ScD, New England Research Institutes, Center for Statistical Analysis and Research, 9 Galen St, Watertown, MA 02472 (E-mail: LSleeper@neriscience.com).

0022-5223/\$36.00

Copyright (C) 2012 by The American Association for Thoracic Surgery doi:10.1016/j.jtcvs.2012.01.016
}

Supplemental material is available online.

The risk of mortality after the Norwood procedure for hypoplastic left heart syndrome (HLHS) and other single right ventricle anomalies with arch obstruction remains significant. Risk factors for death and transplantation after the Norwood procedure may be thought of as occurring in 2 categories: factors intrinsic to the patient that are traditionally considered nonmodifiable, such as anatomic subtype, weight, gestational age, and pulmonary venous obstruction, and modifiable factors that may be subject to practice variation, such as perioperative management, timing of surgery, technique, and perfusion strategies. The Pediatric Heart Network Single Ventricle Reconstruction (PHN SVR) trial prospectively collected preoperative, operative, and postoperative multi-institutional data from more than 500 


$$
\begin{aligned}
& \text { Abbreviations and Acronyms } \\
& \text { AA }=\text { aortic atresia } \\
& \text { AS }=\text { aortic stenosis } \\
& \text { HLHS }=\text { hypoplastic left heart syndrome } \\
& \text { HR }=\text { hazard ratio } \\
& \text { MA }=\text { mitral atresia } \\
& \text { MBTS }=\text { modified Blalock-Taussig shunt } \\
& \text { MS }=\text { mitral stenosis } \\
& \text { OPVR }=\text { obstructed pulmonary venous return } \\
& \text { PHN }=\text { Pediatric Heart Network Single } \\
& \text { SVR } \text { Ventricle Reconstruction } \\
& \text { RVPAS }=\text { right ventricle-to-pulmonary artery } \\
& \text { shunt } \\
& \text { SES }=\text { socioeconomic status }
\end{aligned}
$$

a Norwood procedure and 1 subject who withdrew from the trial in the first week after randomization, and for whom no additional data were collected.

\section{Data Collection}

This report is based on an analysis of early and nonmodifiable patient factors. Detailed information on birth characteristics, patient demographics, and pre-Norwood procedure medical history was collected on standardized forms. Socioeconomic status (SES) was assigned using a US census-based score derived from 6 measures related to income, housing, and occupational-related features of the subject's census block tract ${ }^{3}$ at the time of randomization. Cause of death was assigned by a 5-member panel who arrived at consensus decision on each event after independent review by each member. ${ }^{4}$ The panel consisted of the SVR Study Chair, a pediatric cardiologist, a pediatric cardiac intensivist, and 2 pediatric cardiac surgeons.

Two-dimensional and Doppler echocardiographic data from a standardized echocardiogram obtained before the Norwood procedure were used in this analysis. All echocardiograms were interpreted centrally at a core laboratory (Medical College of Wisconsin). Variables used in this report include right ventricular fractional area change, presence versus absence of antegrade flow in the aorta (patent vs atretic aortic valve), and no/mild versus moderate/severe valve regurgitation (aortic, mitral, tricuspid).

\section{Definitions}

The type of shunt used in the Norwood procedure (MBTS or RVPAS) was defined as the shunt in place at the end of the Norwood procedure, which differed from the randomly assigned shunt for 48 subjects $(9 \%)$. Preterm was defined as gestational age less than 37 weeks. OPVR was defined as the use of postnatal intervention directed at the atrial septum, including balloon septostomy, open atrial septectomy, and urgent Norwood procedure. $^{2}$

\section{Statistical Methods}

The primary end point of the SVR trial was a composite of the earliest occurrence of death or transplant. However, we hypothesized that the hazard functions for death and transplant might differ, as well as the factors associated with those end points. Therefore, outcomes at the time of last follow-up were examined using a competing risks framework. In addition, we hypothesized that the factors associated with these outcomes might differ according to time domain. Parametric regression modeling methodology allowed us to fit early, constant, and late phase hazard functions and to test their significance.

Summary statistics are reported as mean \pm standard deviation or median and interquartile range. Mean or median imputation was used; $2 \%$ or less data were missing in variables on which imputation was performed, with the exception of highest lactate $(18 \%)$ and fractional area change $(8 \%)$. Genetic syndrome and nonsyndromic abnormalities were analyzed with an explicit category for unknown status. All outcomes were measured as time since randomization. The following independent and mutually exclusive states were defined for analysis: death, cardiac transplantation, and transplant-free survival (ie, no transition to another state). Nonparametric Kaplan-Meier estimates of freedom from death and transplantation were obtained and used to inform starting values for parametric model estimation of the hazard functions for each state and the number of phases. Competing risks cumulative incidence event rate estimation was used. Univariate (Table E1) and multivariable modeling were conducted using the parametric regression model. ${ }^{5}$ Bootstrap resampling was used to estimate the reliability of each factor selected by stepwise regression for the multivariable model. ${ }^{6,7}$ We retained main effects in the model if the term had reliability of $50 \%$ or more and a $P$ value less than .05 . In addition to the identification of independent associated factors, the interaction of shunt type with each candidate factor was examined unless there were insufficient events to achieve model convergence. The final multivariable 


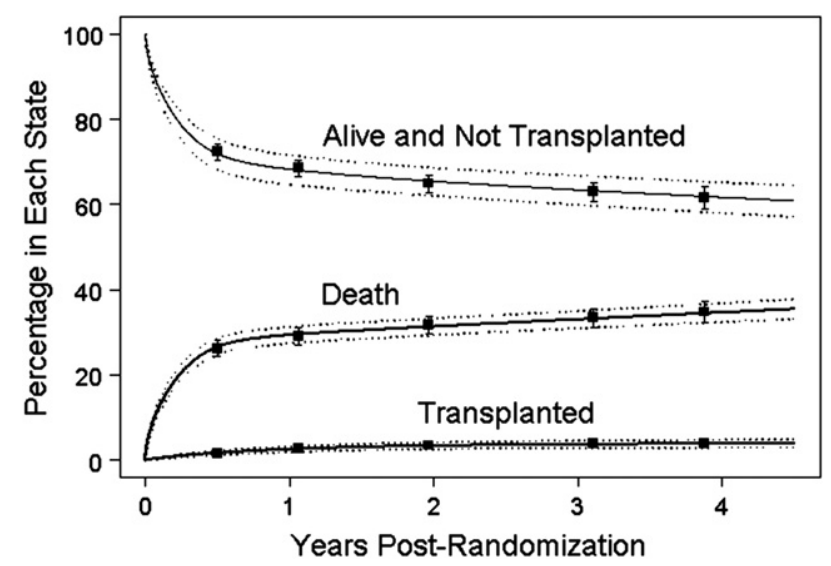

FIGURE 1. Proportion of subjects in each of 3 competing mutually exclusive end states: death, transplant, and alive without transplant for all 549 subjects (solid curves). Dashed curves represent the pointwise 68\% (1 standard error) confidence bands based on the parametric fit. The squares and associated error bars represent the nonparametric estimates \pm 1 standard error.

model was also solved to predict the time-related probability of each state for selected combinations of associated factors representing plausible patient profiles. All analyses were performed using SAS version 9.2 (SAS Institute Inc, Cary, NC) and SAS macros from the Cleveland Clinic. ${ }^{5}$

\section{RESULTS}

The analytic cohort included 549 subjects (MBTS 268, RVPAS 281). The mean follow-up in subjects who survived and did not undergo cardiac transplant was $2.7 \pm 0.9$ years, with a maximum follow-up of 4.4 years. There were 178 deaths: 100 in the MBTS group and 78 in the RVPAS group. More than one third (39\%) were of cardiovascular cause,
$25 \%$ had unknown cause, $10 \%$ were due to multisystem organ failure, $7 \%$ were due to infection, $7 \%$ were of pulmonary cause, $5 \%$ were due to surgical complications, and $7 \%$ were due to other causes. There were 19 transplants: 7 in the MBTS group (all occurring within 1 year of randomization) and 12 in the RVPAS group (half occurring within 1 year of randomization). A genetic syndrome, diagnosed at a median age of 0.5 (interquartile range, 0.1-9.0) months, was present in 26 subjects $(5 \%)$, including 8 with CHARGE association; 5 with Turner syndrome; 4 with Kabuki syndrome; 1 each with DiGeorge, Alagille, Goldenhar, Down, or Thode-Leonard syndrome; and 4 others with unspecified syndromes.

Figure 1 displays competing risk time-related prevalence for the 3 states (death, transplant, survival without transplant). For the entire cohort, the 1- and 3-year mortality rates were $29 \%$ and $33 \%$. The transplant prevalence at 1 and 3 years was $2.5 \%$ and $3.6 \%$, respectively. The parametric curves provide an accurate estimate of the event rates derived from nonparametric modeling (shown by the point estimates). This concordance indicates that the parametric regression model provides a suitable fit to the data and is appropriate for identifying factors associated with each state.

The multivariable model for death included several independent factors and 2 interactions with shunt type (Table 1). The hazard for death was characterized by an early phase and a constant phase that when combined describe the pattern of mortality over time. Clinical factors associated with the constant phase contribute to the likelihood of death equally across the entire time period of analysis. Although early and constant phase factors contribute in varying degrees to the hazard of death across the entire time spectrum,

TABLE 1. Multivariable model for mortality (total $n=549,178$ deaths)

\begin{tabular}{|c|c|c|c|c|}
\hline & Hazard ratio & $95 \%$ CI & $P$ value & Reliability \\
\hline \multicolumn{5}{|l|}{ Early phase } \\
\hline OPVR vs no OPVR & 4.75 & $(2.65-8.52)$ & $<.001$ & $88 \%$ \\
\hline No HLHS vs HLHS with AS/MS & 4.00 & $(1.91-8.37)$ & $<.001$ & \\
\hline No HLHS vs HLHS with AA/MS & 1.75 & $(0.98-3.13)$ & .06 & \\
\hline No HLHS vs HLHS with AS/MA & 1.28 & $(0.46-1.56)$ & .63 & \\
\hline No HLHS vs HLHS with AA/MA & 2.07 & $(1.12-3.82)$ & .021 & \\
\hline Lower SES score (per 5-point decrease) & 1.28 & $(1.06-1.56)$ & .012 & $64 \%$ \\
\hline Smaller ascending aorta diameter, per $\mathrm{mm}$ & 1.23 & $(1.04-1.45)$ & .013 & $63 \%$ \\
\hline RVPAS vs MBTS & & & & $56 \%, 55 \%$ \\
\hline Term, aortic valve not patent & 0.36 & $(0.22-0.60)$ & $<.001$ & \\
\hline Term, aortic valve patent & 0.57 & $(0.49-1.47)$ & .52 & \\
\hline Preterm, aortic valve not patent & 1.25 & $(0.66-2.38)$ & .49 & \\
\hline Preterm, aortic valve patent & 2.97 & $(1.43-6.19)$ & .004 & \\
\hline \multicolumn{5}{|l|}{ Constant phase } \\
\hline Lower gestational age, per wk & 1.56 & $(1.28-1.90)$ & $<.001$ & $50 \%$ \\
\hline Genetic syndrome present vs none & 9.34 & $(3.07-28.40)$ & $<.001$ & $55 \%$ \\
\hline Genetic syndrome unknown vs none & 4.74 & $(2.10-10.72)$ & $<.001$ & $78 \%$ \\
\hline RVPAS vs MBTS* & 1.10 & $(0.43-2.83)$ & .85 & $78 \%$ \\
\hline
\end{tabular}

$A A$, Aortic atresia; $A S$, aortic stenosis; $H L H S$, hypoplastic left heart syndrome; $M A$, mitral atresia; $M B T S$, modified Blalock-Taussig shunt; $R V P A S$, right ventricle-to-pulmonary artery shunt; $M S$, mitral stenosis; $O P V R$, obstructed pulmonary venous return; $S E S$, socioeconomic score. *Shunt type forced into model. 
TABLE 2. Additional pairwise anatomic diagnosis comparisons from multivariable model for death in Table 1

\begin{tabular}{lccc}
\hline Comparison & Hazard ratio & $\mathbf{9 5} \% \mathbf{C I}$ & $\boldsymbol{P}$ value \\
\hline AS/MS vs & & & \\
AA/MA & 0.52 & $(0.23-1.15)$ & .11 \\
AA/MS & 0.44 & $(0.20-0.95)$ & .04 \\
AS/MA & 0.32 & $(0.10-1.00)$ & .05 \\
AA/MA vs & & & \\
AA/MS & 0.84 & $(0.54-1.31)$ & .46 \\
AS/MA & 0.62 & $(0.23-1.67)$ & .35 \\
AA/MS vs AS/MA & 0.73 & $(0.27-1.98)$ & .54 \\
\hline
\end{tabular}

$A A$, Aortic atresia; $A S$, aortic stenosis; $M A$, mitral atresia; $M S$, mitral stenosis.

the early phase factors characterized the hazard predominantly in the first year after the Norwood procedure. After this time, the hazard of death up to 4.4 years was predominantly attributable to constant phase factors. Early phase factors associated with death included lower SES score (hazard ratio $[\mathrm{HR}]=1.28$ per 5-point decrease, a decrement approximately comparing subjects from 2 adjacent SES quartiles, $P=.012$ ), a smaller ascending aorta diameter (HR $=1.23$ per $1 \mathrm{~mm}$ decrease, $P=.014$ ), the presence of OPVR, and certain subtypes of cardiac anatomy (Tables 1 and 2). Subjects with HLHS-aortic stenosis (AS)/mitral atresia (MA), HLHS-AA/mitral stenosis (MS), and a diagnosis other than HLHS were at highest risk of death and had similar mortality. Among subjects with HLHS and AA, there was no difference in mortality among those with MA compared with those with MS $(\mathrm{HR}=0.85, P=.46)$. Mortality was lowest in subjects with HLHS-AS/MS (Table 1). Two factors were associated with a constant hazard of death (both $P<.001$ ): the presence of a genetic syndrome (12/26 subjects with a genetic syndrome died) and lower gestational age $(\mathrm{HR}=1.56$ per decreasing week).

In the multivariable model for death, there were 2 significant 2-way interactions. Shunt type had a significant interaction with preterm status $(P=.029)$ and aortic valve patency $(P=.018)$. Four subgroups resulted from these 2 factors: term infants with an atretic aortic valve $(51 \%$ of subjects), term infants with a patent aortic valve (38\% of subjects), preterm infants with an atretic aortic valve (7\% of subjects), and preterm infants with a patent aortic valve (4\% of subjects). We found no significant benefit of either shunt type for term infants with a patent aortic valve $(P=.57)$ or for preterm infants with an atretic aortic valve $(P=.49)$; this represents approximately half the cohort $(45 \%)$. The RVPAS was associated with lower mortality for term infants with an atretic aortic valve (RVPAS vs MBTS HR $=0.36, P<.001$ ), which represent the other half of the cohort. The MBTS was associated with lower mortality for the small subgroup of preterm infants with a patent aortic valve (RVPAS vs MBTS HR $=2.97$, $P=.004)$.
We used the parametric regression model to generate predicted cumulative incidence of death by cardiac anatomy and shunt type for low-risk subjects (Figure 2, $A$ and $B$ ). The predicted mortality for any patient profile can be obtained from the model. Figure 2, $C$ and $D$, shows selected scenarios of poor outcome in those with HLHS and AA/ MS: Subjects with OPVR who are preterm and have a smaller than average ascending aortic diameter have less than a $20 \%$ chance of survival to 1 year, regardless of shunt type. Because OPVR is a risk factor associated with the early phase of the hazard for death, mortality occurs rapidly (by 6- 8 months, usually before the stage II procedure). Subjects with no OPVR, but who have a genetic syndrome, are preterm, and have a small aortic diameter, also have less than a $20 \%$ chance of survival at 4 years, but the mortality occurs over time, because genetic syndrome is a risk factor associated with the underlying constant (rather than early) hazard of death. Conversely, Figure 2, $E$ and $F$, shows selected scenarios of good outcome. These profiles are for subjects with HLHS with AS/MS (Figure 2,E) or AA/MA (Figure 2, $F$ ) with other characteristics fixed at SES at the third quartile, no OPVR, term status, and an above-average ascending aorta diameter. For these subjects, all have survival more than $70 \%$ at 4 years, regardless of shunt type.

Eight variables were associated with an increased risk of transplant at the $P$ less than .10 level (Table E2). We found no significant interactions of shunt type and other variables. The multivariable model for transplant (Table 3 ) had 3 independent factors: lower right ventricle fractional area change from the pre-Norwood echocardiogram, a diagnosis other than HLHS, and a larger number of pre-Norwood surgeries (Table E2 shows the procedure listing). Shunt type was not associated with transplant (RVPAS vs MBTS HR $=1.46$, $95 \%$ CI, $0.57-3.70, P=.43$ ). The presence of moderate/severe tricuspid regurgitation was also clinically significant $(\mathrm{HR}=2.61)$, but was not statistically significant $(P=.07)$ because of its correlation with cardiac anatomy and number of prior surgeries. Figure 3 shows the cumulative incidence of transplant for 8 patient profiles. For example, $11 \%$ of infants with $35 \%$ fractional area change on pre-Norwood echocardiogram and no pre-Norwood surgery are predicted to undergo transplant by 3 years regardless of anatomy, whereas $27 \%$ to $36 \%$ of infants with HLHS, $25 \%$ fractional area change, and 1 pre-Norwood surgery will undergo transplantation by that time. One high-risk scenario is an infant with a diagnosis other than HLHS, 25\% fractional area change, and 1 pre-Norwood surgery $(62 \%-76 \% 3$-year probability of transplant).

\section{DISCUSSION}

The goal of this analysis of the PHN SVR trial dataset was to identify patient and preoperative factors associated with the intermediate-term occurrence of death and cardiac 

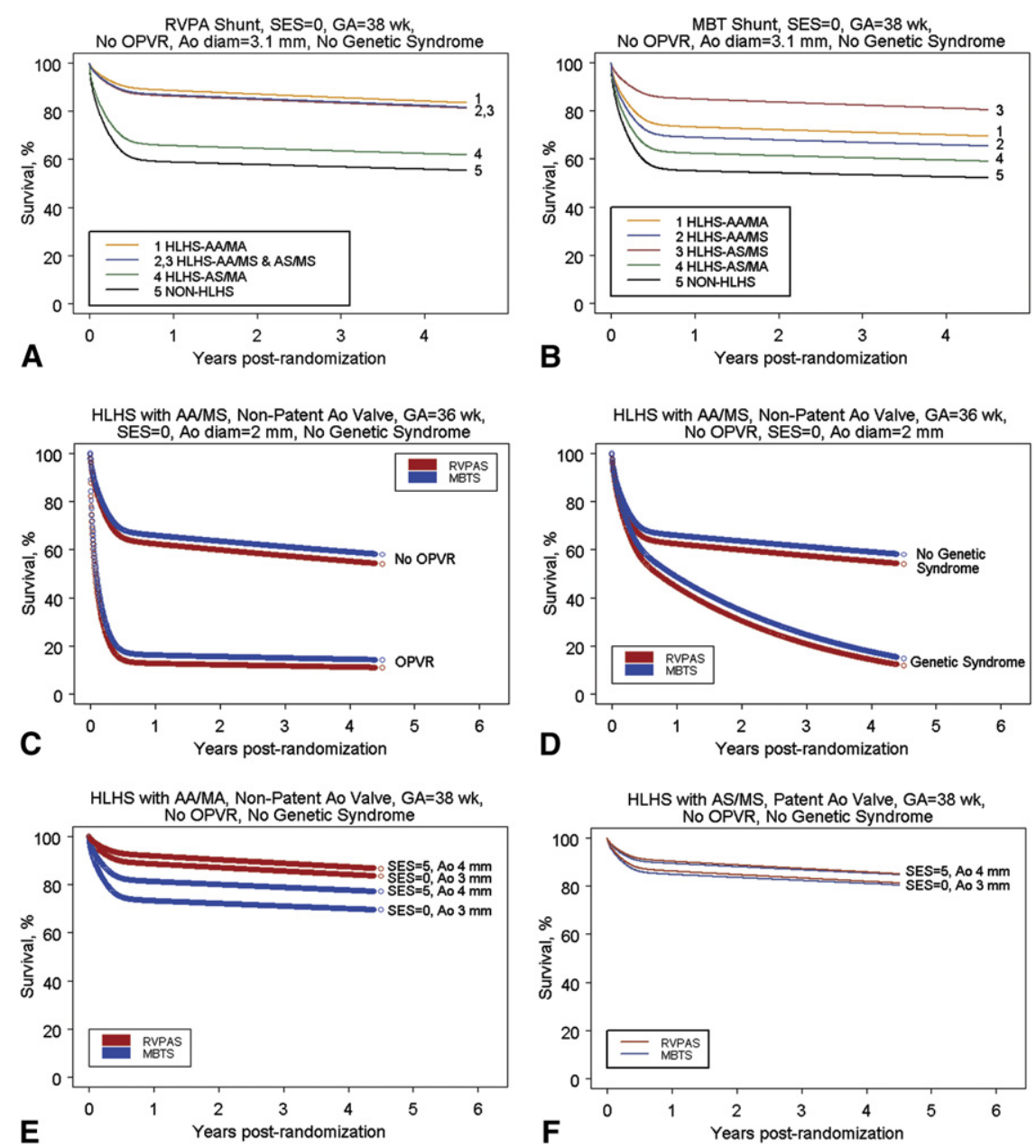

FIGURE 2. A, Parametric survival curve by anatomic subtype of subjects undergoing RVPAS. B, Parametric survival curve by anatomic subtype of subjects undergoing MBTS. C, Parametric survival curve for higher-risk subjects, showing the impact of OPVR on survival among subjects undergoing the Norwood procedure with MBTS versus RVPAS. D, Parametric survival curve for higher-risk subjects showing the impact of a genetic syndrome on survival among subjects undergoing the Norwood procedure with MBTS versus RVPAS. E, Parametric survival curve for lower-risk subjects, showing the impact of shunt type, SES, and aortic diameter on survival of subjects with HLHS-AA/MA. F, Parametric survival curve for lower-risk subjects, showing the impact of shunt type, SES, and aortic diameter on survival of subjects with HLHS-AS/MS. RVPA, Right ventricle-to-pulmonary artery; SES, socioeconomic status; $G A$, gestational age; $O P V R$, obstructed pulmonary venous return; Ao, aorta; diam, diameter; $M S$, mitral stenosis; $M B T$, modified Blalock-Taussig; $H L H S$, hypoplastic left heart syndrome; $A A$, aortic atresia; $M A$, mitral atresia.

transplant in infants with single right ventricle anomalies undergoing staged palliation. The candidate factors chosen for this analysis include those with little or no potential for modification before surgery. Because these characteristics

TABLE 3. Multivariable model for cardiac transplantation

\begin{tabular}{lcccc}
\hline \multicolumn{1}{c}{ Variable } & $\begin{array}{c}\text { Hazard } \\
\text { ratio }\end{array}$ & $\mathbf{9 5 \%}$ CI & $\begin{array}{c}\boldsymbol{P} \\
\text { value }\end{array}$ & Reliability \\
\hline RVPAS vs MBTS* & 1.46 & $(0.57-3.70)$ & .43 & - \\
Lower pre-Norwood RV & $1.49 \dagger$ & $(1.12-1.97)$ & .006 & $60 \%$ \\
$\quad$ fractional area change, $\%$ & & & & \\
HLHS vs other diagnosis & 0.32 & $(0.11-0.89)$ & .029 & $51 \%$ \\
No. of pre-Norwood surgeries & 5.64 & $(1.69-18.77)$ & .005 & $54 \%$ \\
\hline
\end{tabular}

HLHS, Hypoplastic left heart syndrome; MBTS, Modified Blalock-Taussig shunt; $R V$, right ventricle; RVPAS, right ventricle-to-pulmonary artery shunt. *Shunt type was forced into the model. $\nmid$ Per 5-unit decrease. are unique to each patient at the time of diagnosis, they are the factors the teams caring for these neonates must use to formulate decisions before surgical intervention. Primarily nonmodifiable factors were chosen with the additional goal of identifying those patient-specific factors that might allow better assignment to an MBTS or RVPAS for the Norwood procedure.

By using parametric regression, we characterized the hazard of death as having a constant phase and an early phase. Many of these risk factors, specifically OPVR, shunt type, smaller ascending aorta, non-HLHS anatomy, genetic syndromes, and lower gestational age, have been identified in previous retrospective and prospective studies. ${ }^{1,8-12}$

Although a genetic syndrome was present in only $5 \%$ of the cohort, it had a strong negative association with 


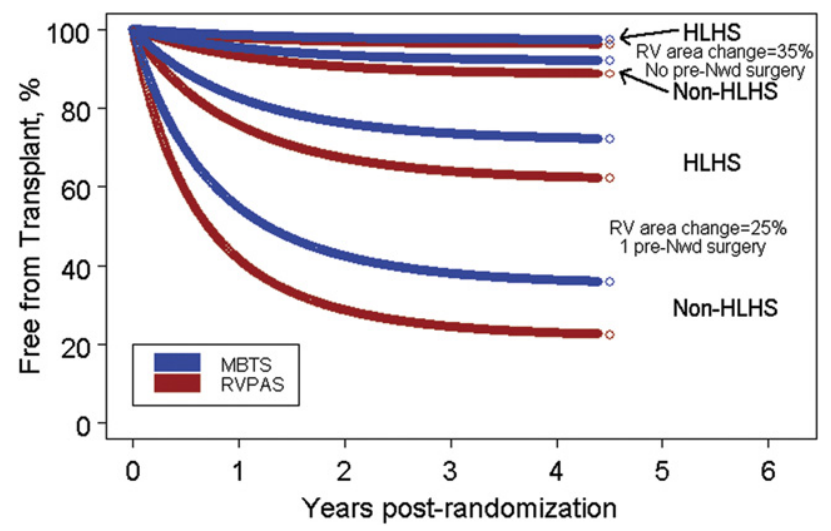

FIGURE 3. Predicted probability of freedom from transplant for subjects with differing cardiac anatomy, right ventricle function, and numbers of pre-Norwood surgeries. $H L H S$, Hypoplastic left heart syndrome; $R V$, right ventricle; MBTS, modified Blalock-Taussig shunt; RVPAS, right ventricleto-pulmonary artery shunt; $N w d$, Norwood.

survival. Only 14 of 26 subjects with an identified genetic syndrome were alive at last follow-up. In a recent analysis of the Society of Thoracic Surgeons and Congenital Heart Surgeons' Society databases, the risk of death after the Norwood procedure among patients with chromosomal defects, the majority of which were Turner syndrome, was increased and found to be greatest within the first year of the Norwood procedure. ${ }^{13}$ Likewise, we found that 10 of the 12 deaths occurring in subjects with a genetic syndrome occurred in the first year. The specific mechanism of increased risk of mortality is unknown but is likely due to abnormalities of organ system function specific to each genetic syndrome. ${ }^{12,13}$ The poor survival of this group is important to consider during prenatal and preoperative counseling.

The presence of OPVR also had a high impact on mortality. This condition is associated with profound hypoxia and the need for an emergency Norwood procedure or a pre-Norwood intervention. Although creation of an unrestrictive atrial septal communication can usually be accomplished at the time of surgery, these patients frequently have persistent abnormalities of the pulmonary vasculature. The wall of the pulmonary veins can be thickened by the presence of multiple elastic lamina, normally not seen in pulmonary veins. ${ }^{14,15}$ Despite anatomic decompression of the left atrium, these patients have ongoing hypoxia with a pulmonary vascular bed unsuitable for subsequent single ventricle palliation. Although we have confirmed the profound risk associated with OPVR, effective treatment remains elusive. Attempts at prenatal intervention are promising but as yet have not resulted in significantly improved outcomes. ${ }^{15}$

There were important differences in survival with respect to anatomic subtype. Consistent with single-center reports, subjects with a non-HLHS diagnosis, such as unbalanced atrioventricular canal defect, double-outlet right ventricle with MA, or heterotaxy syndrome, had poorer survival. ${ }^{10}$ The superior survival among subjects with AS/MS was observed even after adjustment for ascending aortic diameter but may be due in part to the presence of antegrade flow with more reliable coronary circulation and possibly a larger aortic root and arch, simplifying the Norwood procedure. Furthermore, the presence of even a small left ventricle that can contribute to cardiac output may be helpful. Two large single-center retrospective studies have suggested that patients with AA/MS may be at higher risk for death after stage 1 palliation, possibly because of the higher prevalence of coronary artery fistulas. ${ }^{16,17}$ In this analysis, there was no significant difference in mortality between subjects with AA and MA and those with AA and MS. Our data do not provide justification for alternative strategies in this group of patients.

We found an important interaction between shunt type and aortic valve patency, as well as between shunt type and prematurity, in association with early phase mortality. Specifically, term infants with an atretic aortic valve had better survival if they underwent an RVPAS compared with an MBTS. The benefit of the RVPAS at 12 months, as previously reported for the SVR trial, seems to be confined, based on a mean follow-up of $2.7 \pm 0.9$ years, to this group of 272 subjects ( $51 \%$ of the total cohort). ${ }^{1}$ The risk of mortality for a term patient with an atretic aortic valve undergoing an RVPAS was one third that of a similar patient undergoing an MBTS. In contrast, among 21 preterm infants ( $4 \%$ of the cohort) with a patent aortic valve, survival was better with an MBTS. For the $45 \%$ of the subjects outside of these 2 groups (ie, term patients with a patent aortic valve and preterm patients with AA), we were unable to demonstrate a significant association between shunt type and mortality. Among the postulated benefits of the RVPAS is improved coronary artery perfusion. ${ }^{18-20}$ The RVPAS results in a higher diastolic pressure, and thus a higher coronary artery driving pressure, which may provide an important benefit to the patient with AA. In contrast with patients with a patent aortic valve, patients with AA are more likely to have coronary artery anomalies including fistulas. ${ }^{21,22}$ Furthermore, patients with an atretic aortic valve are more likely to have a smaller ascending aorta, making surgical construction of an unobstructed connection between the ascending aorta and the main pulmonary artery more technically challenging. Indeed, obstruction in this connection, which can impair coronary artery blood flow in the presence of AA, has been cited as a cause of death among patients undergoing the Norwood procedure. ${ }^{23}$ The more favorable hemodynamics of the RVPAS may ameliorate mild obstruction that could otherwise result in critical coronary artery insufficiency, myocardial ischemia, and death among similar patients with an MBTS. Therefore, the benefit of the RVPAS over the MBTS in term newborns with AA may be explained by 
better coronary artery blood flow. Why an MBTS would be favorable among preterm subjects with a patent aortic valve is less clear. Perhaps the ventriculotomy in a small heart is less well tolerated and overwhelms other risk factors. It must be emphasized that only $11 \%$ of the subjects in this trial were preterm.

This analysis studied factors that are known about the newborn with HLHS before surgical intervention and that are the basis for decision-making by the teams caring for the patient with HLHS. They are generally considered nonmodifiable, but in fact 2 of the factors, gestational age and SES, might be modifiable. This study and single-center studies of outcome have identified the importance of gestational age as a risk factor for mortality, as well as for neurodevelopmental outcome. ${ }^{9-12}$ Although some early deliveries are inevitable, the increased risk of mortality should be taken into consideration if earlier elective delivery is considered. In the case of SES, the impact on survival is thought to be due to limited access to health care resources. ${ }^{24}$ Therefore, provision of services to compensate for the challenges associated with low SES may positively affect outcome.

Given the high mortality of subjects after the Norwood procedure, it seems at first surprising that there was such a low use of transplantation. Although the decisionmaking process concerning the use of transplantation in this group is beyond the scope of this study, it is noteworthy that many of the factors associated with mortality, such as OPVR and a genetic syndrome, are often considered contraindications for transplant. ${ }^{25}$ Furthermore, multiorgan dysfunction that occurs as a consequence of inadequate cardiac output after the Norwood procedure may also preclude the use of transplantation as salvage therapy. The relative lack of donor availability also limits use of this therapy. These data suggest that transplantation may be an alternative for only a small fraction of patients at risk for mortality after the Norwood procedure.

\section{Study Limitations}

This analysis has several limitations. We had limited power to detect interactions of shunt type and patient subgroup when subgroup sizes were small and to detect differences in mortality for selected subgroups regardless of shunt. For example, the difference in mortality between patients with HLHS with AA/MA versus those with AS/ MS was 2-fold, clinically significant, but of marginal statistical significance. There was also low power to identify statistically significant risk factors for transplantation because of the small number of such events. Nevertheless, the risk models developed for both mortality and transplantation included multiple independent factors and have clinical relevance. Finally, the presence versus absence of a genetic syndrome was unknown for one third of subjects, and the increased HR for death relative to subjects without a genetic syndrome reflects in part mortality that occurred before a genetic evaluation could be performed.

\section{CONCLUSIONS}

These data suggest that term patients with AA have better outcomes with an RVPAS and that preterm infants with a patent aortic valve may have better outcomes with an MBTS. For slightly less than half of the cohort, nonmodifiable factors did not aid in shunt selection. Lower gestational age and SES, as well as the presence of a genetic syndrome, are also independent predictors of mortality. Transplant was used in only $3 \%$ of subjects after the Norwood procedure. Right ventricular function and anatomy, but not shunt type, were associated with transplantation. Patient-specific factors associated with mortality after the Norwood procedure are frequently contraindications to transplantation. Effective alternative therapies for the highest-risk Norwood candidates remain elusive.

The authors thank Dr Eugene Blackstone and Jeevanantham Rajeswaran for guidance on this analysis.

\section{References}

1. Ohye RG, Sleeper LA, Mahony L, Newburger JW, Pearson GD, Lu M, et al. Comparison of shunt types in the Norwood procedure for single-ventricle lesions. N Engl J Med. 2010;362:1980-92.

2. Ohye RG, Gaynor JW, Ghanayem NS, Goldberg CS, Laussen PC, Frommelt PC, et al. Design and rationale of a randomized trial comparing the Blalock-Taussig and right ventricle-pulmonary artery shunts in the Norwood procedure. $J$ Thorac Cardiovasc Surg. 2008;136:968-75.

3. Diez Roux AV, Merkin SS, Arnett D, Chambless L, Massing M, Nieto FJ, et al. Neighborhood of residence and incidence of coronary heart disease. $N$ Engl $J$ Med. 2001;345:99-106.

4. Ohye RG, Schonbeck JV, Eghtesady P, Laussen PC, Pizarro C, Shrader P, et al. Cause, timing, and location of death in the Single Ventricle Reconstruction Trial. $J$ Thorac Cardiovasc Surg. (in press).

5. Blackstone EH, Naftel DC, Turner ME. The decomposition of time-varying hazard into phases, each incorporating a separate stream of concomitant Information. Am Stat Assoc. 1986;81:615-24.

6. Breiman L. Bagging predictors. Machine Learning. 1996;24:123-40.

7. Efron B, Tibshirani RJ. An Introduction to the Bootstrap. Boca Raton, FL: CRC Press LLC; 1998.

8. Ashburn DA, McCrindle BW, Tchervenkov CI, Jacobs ML, Lofland GK, Bove EL, et al. Outcomes after the Norwood operation in neonates with critical aortic stenosis or aortic valve atresia. J Thorac Cardiovasc Surg. 2003;125: 1070-82.

9. Ghanayem NS, Hoffman GM, Mussatto KA, Frommelt MA, Cava JR, Mitchell ME, et al. Perioperative monitoring in high-risk infants after stage 1 palliation of univentricular congenital heart disease. J Thorac Cardiovasc Surg. 2010;140:857-63.

10. Stasik CN, Gelehrter S, Goldberg CS, Bove EL, Devaney EJ, Ohye RG. Current outcomes and risk factors for the Norwood procedure. J Thorac Cardiovasc Surg. 2006;131:412-7.

11. Artrip JH, Campbell DN, Ivy DD, Almodovar MC, Chan KC, Mitchell MB, et al. Birth weight and complexity are significant factors for the management of hypoplastic left heart syndrome. Ann Thorac Surg. 2006;82:1252-9.

12. Gaynor JW, Mahle WT, Cohen MI, Ittenbach RF, DeCampli WM, Steven JM, et al. Risk factors for mortality after the Norwood procedure. Eur J Cardiothorac Surg. 2002;22:82-9.

13. Patel A, Hickey E, Mavroudis C, Jacobs JP, Jacobs ML, Backer CL, et al. Impact of noncardiac congenital and genetic abnormalities on outcomes in hypoplastic left heart syndrome. Ann Thorac Surg. 2010;89:1805-14. 
14. Rychik J, Rome JJ, Collins MH, DeCampli WM, Spray TL. The hypoplastic left heart syndrome with intact atrial septum: atrial morphology, pulmonary vascular histopathology and outcome. J Am Coll Cardiol. 1999;34:554-60.

15. Vida VL, Bacha EA, Larrazabal A, Gauvreau K, Thiagaragan R, FynnThompson F, et al. Hypoplastic left heart syndrome with intact or highly restrictive atrial septum: surgical experience from a single center. Ann Thorac Surg. 2007;84:581-6.

16. Vida VL, Bacha EA, Larrazabal A, Gauvreau K, Dorfman AL, Marx G, et al. Surgical outcome for patients with the mitral stenosis-aortic atresia variant of hypoplastic left heart syndrome. J Thorac Cardiovasc Surg. 2008;135:339-46.

17. Glatz JA, Fedderly RT, Ghanayem NS, Tweddell JS. Impact of mitral stenosis and aortic atresia on survival in hypoplastic left heart syndrome. Ann Thorac Surg. 2008;85:2057-62

18. Bradley SM, Simsic JM, McQuinn TC, Habib DM, Shirali GS, Atz AM. Hemodynamic status after the Norwood procedure: a comparison of right ventricle-topulmonary artery connection versus modified Blalock-Taussig shunt. Ann Thorac Surg. 2004;78:933-41

19. Pizarro C, Norwood WI. Right ventricle to pulmonary artery conduit has a favorable impact on postoperative physiology after Stage I Norwood: preliminary results. Eur J Cardiothorac Surg. 2003;23:991-5.

20. Cua CL, Thiagarajan RR, Gauvreau K, Lai L, Costello JM, Wessel DL, et al. Early postoperative outcomes in a series of infants with hypoplastic left heart syndrome undergoing stage 1 palliation operation with either modified Blalock-Taussig shunt or right ventricle to pulmonary artery conduit. Pediatr Crit Care Med. 2006; 7:238-44.

21. Smith A, Pozzi M, Anderson RH. The morphology of hypoplasia of the left heart. In: Anderson RH, Pozzi M, Hutchinson S, eds. Hypoplastic Left Heart Syndrome. London: Springer-Verlag; 2005:1-18.

22. Baffa JM, Chen SL, Guttenberg ME, Norwood WI, Weinberg PM. Coronary artery abnormalities and right ventricular histology in hypoplastic left heart syndrome. J Am Coll Cardiol. 1992;20:350-8.

23. Bartram U, Grunenfelder J, Van Praagh R. Causes of death after the modified Norwood procedure: a study of 122 postmortem cases. Ann Thorac Surg. 1997;64:1795-802.

24. Mackie AS, Gauvreau K, Newburger JW, Mayer JE, Erickson LC. Risk factors for readmission after neonatal cardiac surgery. Ann Thorac Surg. 2004;78: 1972-8.

25. Jenkins PC, Flanagan MF, Jenkins KJ, Sargent JD, Canter CE, Chinnock RE, et al. Survival analysis and risk factors for mortality in transplantation and staged surgery for hypoplastic left heart syndrome. J Am Coll Cardiol. 2000;36: $1178-85$.

\section{APPENDIX}

National Heart, Lung, and Blood Institute: Gail Pearson, Victoria Pemberton, Rae-Ellen Kavey,* Mario Stylianou, Marsha Mathis*

Network Chair: University of Texas Southwestern Medical Center, Lynn Mahony

Data Coordinating Center: New England Research Institutes, Lynn Sleeper (principal investigator [PI]), Sharon Tennstedt (PI), Steven Colan, Lisa Virzi,* Patty Connell,* Victoria Muratov, Lisa Wruck,* Minmin Lu, Dianne Gallagher, Anne Devine, * Julie Schonbeck, Thomas Travison,* David F. Teitel

Core Clinical Site Investigators: Children's Hospital Boston, Jane W. Newburger (PI), Peter Laussen, Pedro del Nido, Roger Breitbart, Jami Levine, Ellen McGrath, Carolyn Dunbar-Masterson, John E. Mayer, Jr, Frank Pigula, Emile A. Bacha, Francis Fynn-Thompson; Children's Hospital of New York, Wyman Lai (PI), Beth Printz,* Daphne Hsu,* William Hellenbrand, Ismee Williams, Ashwin Prakash,* Seema Mital,* Ralph Mosca,* Darlene Servedio,*

\footnotetext{
* No longer at the institution listed.
}

Rozelle Corda, Rosalind Korsin, Mary Nash;* Children's Hospital of Philadelphia, Victoria L. Vetter (PI), Sarah Tabbutt,* J. William Gaynor (Study Co-Chair), Chitra Ravishankar, Thomas Spray, Meryl Cohen, Marisa Nolan, Stephanie Piacentino, Sandra DiLullo,* Nicole Mirarchi; Cincinnati Children's Medical Center, D. Woodrow Benson (PI), Catherine Dent Krawczeski, Lois Bogenschutz, Teresa Barnard, Michelle Hamstra, Rachel Griffiths, Kathryn Hogan, Steven Schwartz, * David Nelson, Pirooz Eghtesady;* North Carolina Consortium: Duke University, East Carolina University, Wake Forest University, Page A.W. Anderson (PI) (deceased), Jennifer Li (PI), Wesley Covitz, Kari Crawford,* Michael Hines, James Jaggers,* Theodore Koutlas, Charlie Sang, Jr, Lori Jo Sutton, Mingfen Xu; Medical University of South Carolina, J. Philip Saul (PI), Andrew Atz, Girish Shirali, Scott Bradley, Eric Graham, Teresa Atz, Patricia Infinger; Primary Children's Medical Center and the University of Utah, Salt Lake City, Utah, L. LuAnn Minich (PI), John A. Hawkins (deceased), Michael Puchalski, Richard V. Williams, Peter C. Kouretas, Linda M. Lambert, Marian E. Shearrow, Jun A. Porter;* Hospital for Sick Children, Toronto, Brian McCrindle (PI), Joel Kirsh, Chris Caldarone, Elizabeth Radojewski, Svetlana Khaikin, Susan McIntyre, Nancy Slater; University of Michigan, Caren S. Goldberg (PI), Richard G. Ohye (Study Chair), Cheryl Nowak;* Children's Hospital of Wisconsin and Medical College of Wisconsin, Nancy S. Ghanayem (PI), James S. Tweddell, Kathleen A. Mussatto, Michele A. Frommelt, Peter C. Frommelt, Lisa Young-Borkowski

Auxiliary sites: Children's Hospital Los Angeles, Alan Lewis (PI), Vaughn Starnes, Nancy Pike; The Congenital Heart Institute of Florida, Jeffrey P. Jacobs (PI), James A. Quintessenza, Paul J. Chai, David S. Cooper,* J. Blaine John, James C. Huhta, Tina Merola, Tracey Griffith; Emory University, William Mahle (PI), Kirk Kanter, Joel Bond,* Jeryl Huckaby; Nemours Cardiac Center, Christian Pizarro (PI), Carol Prospero; Julie Simons, Gina Baffa, Wolfgang A. Radtke; University of Texas Southwestern Medical Center, Ilana Zeltzer (PI), Tia Tortoriello,* Deborah McElroy, Deborah Town

Angiography Core Laboratory: Duke University, John Rhodes, J. Curt Fudge

Echocardiography Core Laboratories: Children's Hospital of Wisconsin, Peter Frommelt; Children's Hospital Boston, Gerald Marx

Genetics Core Laboratory: Children's Hospital of Philadelphia, Catherine Stolle

Protocol Review Committee: Michael Artman (Chair), Erle Austin, Timothy Feltes, Julie Johnson, Thomas Klitzner, Jeffrey Krischer, G. Paul Matherne

Data and Safety Monitoring Board: John Kugler (Chair), Rae-Ellen Kavey (Executive Secretary), David J. Driscoll, Mark Galantowicz, Sally A. Hunsberger, Thomas J. Knight, Holly Taylor, Catherine L. Webb 
TABLE E1. Patient characteristics and association with mortality by phase

\begin{tabular}{|c|c|c|c|c|c|}
\hline \multirow[b]{2}{*}{ Variable } & \multirow[b]{2}{*}{ Mean \pm SD or $\%$} & \multicolumn{2}{|c|}{ Early phase } & \multicolumn{2}{|c|}{ Constant phase } \\
\hline & & HR & $P$ value & HR & $P$ value \\
\hline RVPAS vs MBTS & $51 \%$ vs $49 \%$ & 0.58 & .002 & 1.64 & .32 \\
\hline \multicolumn{6}{|l|}{ Prenatal } \\
\hline Prenatal diagnosis & $77 \%$ & .87 & .45 & 1.89 & .38 \\
\hline Fetal intervention & $2.7 \%$ & - & - & - & - \\
\hline \multicolumn{6}{|l|}{ Birth } \\
\hline Gestational age, wk & $38.2 \pm 1.6$ & .89 & .030 & 0.65 & $<.001$ \\
\hline Gestational age $<37 \mathrm{wk}$ & $12 \%$ & 2.31 & $<.001$ & 3.61 & .028 \\
\hline Apgar at $1 \mathrm{~min}$ & $7.6 \pm 1.6$ & 0.94 & .21 & 0.997 & .94 \\
\hline Apgar at $5 \mathrm{~min}$ & $8.6 \pm 0.8$ & .85 & .07 & 0.89 & .61 \\
\hline Birth weight, kg & $3.10 \pm 5.41$ & 0.59 & .001 & 0.69 & .42 \\
\hline Birth weight $<2.5 \mathrm{~kg}$ & $14 \%$ & 2.10 & $<.001$ & 2.13 & .21 \\
\hline Birth weight $<1.5 \mathrm{~kg}$ & $0.4 \%$ & 2.96 & .29 & 18.4 & .006 \\
\hline \multicolumn{6}{|l|}{ Demographic } \\
\hline Male & $62 \%$ & 0.81 & .22 & 2.04 & .25 \\
\hline Hispanic & $19 \%$ & 1.06 & .88 & 0.58 & .68 \\
\hline White race & $80 \%$ & 0.80 & .27 & 0.68 & .50 \\
\hline SES score, US census (HR per 5-point decrease) & $0.05 \pm 5.08$ & 1.27 & .006 & 0.88 & .57 \\
\hline \multicolumn{6}{|l|}{ Anatomy } \\
\hline HLHS & $88 \%$ & 0.60 & .019 & 1.90 & .54 \\
\hline AA, MA & $38 \%$ & 0.93 & .69 & 1.14 & .81 \\
\hline AA, MS & $25 \%$ & 1.22 & .49 & 0.44 & .40 \\
\hline AS, MS & $12 \%$ & 0.32 & .008 & 2.22 & .19 \\
\hline Any AA & $62 \%$ & 1.07 & .70 & 0.53 & .25 \\
\hline Obstructed PV drainage & $3.5 \%$ & 4.30 & $<.001$ & Not estimable & \\
\hline Total anomalous pulmonary venous return & $1.6 \%$ & 2.09 & .33 & 8.25 & .27 \\
\hline Ascending aorta diameter, $\mathrm{mm}$ & $3.15 \pm 1.75$ & 0.87 & .018 & 1.07 & .56 \\
\hline \multicolumn{6}{|l|}{ Genetic syndrome } \\
\hline Yes vs no & $5 \%$ & 1.48 & .45 & 7.91 & .001 \\
\hline Unknown vs no & $32 \%$ & 3.30 & $<.001$ & 2.78 & .049 \\
\hline \multicolumn{6}{|l|}{ Non-syndromic abnormality } \\
\hline Yes vs no & $19 \%$ & 0.77 & .43 & 2.02 & .22 \\
\hline Unknown vs no & $32 \%$ & 3.00 & $<.001$ & 2.89 & .05 \\
\hline \multicolumn{6}{|l|}{ Pre-Norwood echocardiography } \\
\hline Patent aortic valve & $42 \%$ & 0.88 & .35 & 1.66 & .28 \\
\hline ASD mean Doppler gradient, $\mathrm{mm} \mathrm{Hg}$ & $5.0 \pm 3.0$ & 1.02 & .55 & 0.97 & .69 \\
\hline $\mathrm{RV}$ fractional area change & $0.35 \pm 0.09$ & 2.07 & .49 & 0.63 & .91 \\
\hline LV present & $69 \%$ & 0.95 & .77 & 1.26 & .68 \\
\hline Moderate/severe tricuspid regurgitation & $12 \%$ & 1.24 & .42 & 2.54 & .13 \\
\hline Moderate/severe mitral regurgitation & $4 \%$ & 0.41 & .29 & .008 & .58 \\
\hline Moderate/severe aortic valve regurgitation & $0.8 \%$ & 0.10 & .54 & $\sim 0$ & .40 \\
\hline \multicolumn{6}{|l|}{ Preoperative } \\
\hline Median highest lactate, mmol/L (IQR) & $3.1(2.5,4.5)$ & 1.06 & .018 & 0.84 & .26 \\
\hline Mechanical ventilation & $48 \%$ & 1.73 & .002 & 0.97 & .95 \\
\hline Pre-Norwood apnea & $14 \%$ & 1.34 & .18 & 0.94 & .89 \\
\hline Pre-Norwood shock & $2.6 \%$ & - & - & - & - \\
\hline Pre-Norwood respiratory failure & $13 \%$ & 1.09 & .76 & 3.02 & .045 \\
\hline Pre-Norwood metabolic acidosis & $5.7 \%$ & 1.05 & .99 & 0.69 & .97 \\
\hline Pre-Norwood catheter intervention & $5.1 \%$ & 2.24 & .005 & 0 & .95 \\
\hline No. of pre-Norwood catheter intervention (median [IQR]) & $\begin{array}{c}0.07 \pm 0.32 \\
(0[0-0])\end{array}$ & 2.24 & .005 & $\sim 0$ & .95 \\
\hline Pre-Norwood noncardiac surgery & $1.5 \%$ & 0.53 & .69 & 4.55 & .19 \\
\hline Pre-Norwood any surgery & $2.0 \%$ & - & - & - & - \\
\hline No. of pre-Norwood total surgeries (median [IQR]) & $\begin{array}{c}0.02 \pm 0.17 \\
(0[0-0])\end{array}$ & 1.21 & .61 & 1.42 & .75 \\
\hline
\end{tabular}


TABLE E1. Continued

\begin{tabular}{|c|c|c|c|c|c|}
\hline \multirow[b]{2}{*}{ Variable } & \multirow[b]{2}{*}{ Mean \pm SD or $\%$} & \multicolumn{2}{|c|}{ Early phase } & \multicolumn{2}{|c|}{ Constant phase } \\
\hline & & HR & $P$ value & HR & $P$ value \\
\hline Pre-Norwood complications & $28 \%$ & 1.57 & .011 & 1.14 & .80 \\
\hline No. of pre-Norwood complications (median [IQR]) & $\begin{array}{c}0.58 \pm 1.23 \\
(0[0-1])\end{array}$ & 1.16 & .003 & 0.91 & .71 \\
\hline
\end{tabular}

$S D$, Standard deviation; HR, hazard ratio; RVPAS, right ventricle-to-pulmonary artery shunt; MBTS, modified Blalock-Taussig shunt; SES, socioeconomic status; HLHS, hypoplastic left heart syndrome; $A S D$, atrial septal defect; $I Q R$, interquartile range; $L V$, left ventricle.

TABLE E2. Results summary for cardiac transplant risk factors with univariate $P$ value less than .2 and for shunt type

\begin{tabular}{|c|c|c|c|c|c|}
\hline \multirow[b]{2}{*}{ Variable } & Transplant & No transplant & \multirow[b]{2}{*}{ Hazard ratio } & \multirow[b]{2}{*}{$95 \%$ CI } & \multirow[b]{2}{*}{$P$ value } \\
\hline & \multicolumn{2}{|c|}{ Mean \pm SD or $\%(n)$} & & & \\
\hline $\mathrm{N}$ & 19 & 530 & & & \\
\hline RVPAS vs MBTS & $63 \%(12)$ & $51 \%(269)$ & 1.43 & $(0.56-3.63)$ & .45 \\
\hline Male vs female & $42 \%(8)$ & $63 \%(332)$ & 0.42 & $(0.17-1.04)$ & .06 \\
\hline $\begin{array}{l}\text { Percentage in census tract below } \\
\text { federal poverty level }\end{array}$ & $7.6 \pm 7.2$ & $13.1 \pm 12.4$ & 1.31 per $5 \%$ increase & $(0.96-1.80)$ & .09 \\
\hline HLHS & $74 \%(14)$ & $88 \%(467)$ & 0.33 & $(0.19-0.55)$ & .03 \\
\hline HLHS with AS/MS & $5 \%(1)$ & $21 \%(109)$ & 0.18 & $(0.02-1.36)$ & .10 \\
\hline HLHS with AS/MA & $11 \%(2)$ & $3 \%(15)$ & 4.05 & $(0.94-17.5)$ & .06 \\
\hline $\begin{array}{l}\text { Total anomalous pulmonary venous } \\
\text { connection }\end{array}$ & $5 \%(1)$ & $2 \%(8)$ & 6.03 & $(0.80-45.6)$ & .08 \\
\hline $\begin{array}{l}\text { Pre-Norwood moderate/severe } \\
\text { tricuspid regurgitation }\end{array}$ & $32 \%(6)$ & $11 \%(59)$ & 3.86 & $(2.29-6.18)$ & .006 \\
\hline Pre-Norwood RV fractional area change & $0.30 \pm 0.09$ & $0.35 \pm 0.08$ & 1.43 per 5 -unit decrease & $(1.09-1.85)$ & .009 \\
\hline Total No. of pre-Norwood surgeries* & $0.11 \pm 0.46$ & $0.02 \pm 0.15$ & 4.21 & $(1.30-13.7)$ & .017 \\
\hline
\end{tabular}

